\title{
From The Editor
}

Our May issue brings new thoughts and ideas from authors with a variety of perspectives of business and management. For example the first paper in this issue, "An Expansion of the Beneficial Outcomes Associated with the Proactive Employee” by Slatten, K. Carson, Baker, and P. Carson examines perceptions of proactive employees in relation to several other factors such as work-group cohesion, compassion satisfaction, burnout, and job withdrawal intentions. The authors analyze data from a large sample of 242 respondent-employees and present interesting findings related to employees indicating a proactive perspective.

Mahjoub and Khamoussi are the authors of the second paper presented in this issue, "Communication about environmental information: what drives the effect on income smoothing as proxy of earnings quality?" emphasizes the growing concern with corporate social responsibility. A focus on non-financial reporting of environmental and social impacts is something all managers must address depending upon the pressures of any given industry and society. The authors find that firms that report non-financial measures are less likely to smooth earnings and a broader discussion of non-financial measures and reporting is discussed.

Our final paper in this May issue focuses on organizational citizenship behavior and what motivates individuals to engage in positive citizenship behaviors. Duffy and Lilly present, "Do Individual Needs Moderate the Relationships between Organizational Citizenship Behavior, Organizational Trust and Perceived Organizational Support?" The authors include organizational trust and individual needs in their exploration of organizational citizenship and tested hypothesized relationships related to each. Findings presented are quite intriguing and provide useful information in understanding individual needs and organizational citizenship. issue.

I look forward to your feedback and appreciate your support. I hope you enjoy our May

Angela Young 